\title{
Bald scalp in men with androgenetic alopecia retains hair follicle stem cells but lacks CD200-rich and CD34-positive hair follicle progenitor cells
}

Luis A. Garza, ${ }^{1}$ Chao-Chun Yang,, ${ }^{2,3}$ Tailun Zhao, ${ }^{1}$ Hanz B. Blatt, ${ }^{1}$ Michelle Lee, ${ }^{1}$ Helen He, ${ }^{1}$ David C. Stanton, ${ }^{4}$ Lee Carrasco, ${ }^{4}$ Jeffrey H. Spiegel, ${ }^{5}$ John W. Tobias, ${ }^{6}$ and George Cotsarelis ${ }^{1}$

\begin{abstract}
1Department of Dermatology, Kligman Laboratories, University of Pennsylvania School of Medicine, Philadelphia, Pennsylvania, USA.
${ }^{2}$ Department of Dermatology and ${ }^{3}$ nnstitute of Clinical Medicine, College of Medicine, National Cheng Kung University, Tainan, Taiwan. ${ }^{4}$ Department of Oral and Maxillofacial Surgery, University of Pennsylvania School of Dental Medicine and University of Pennsylvania Health System, Philadelphia, Pennsylvania, USA. ${ }^{5}$ Department of Plastic Surgery, Boston University, Boston, Massachusetts, USA. ${ }^{6}$ Penn Bioinformatics Core, University of Pennsylvania School of Medicine, Philadelphia, Pennsylvania, USA
\end{abstract}

\begin{abstract}
Androgenetic alopecia (AGA), also known as common baldness, is characterized by a marked decrease in hair follicle size, which could be related to the loss of hair follicle stem or progenitor cells. To test this hypothesis, we analyzed bald and non-bald scalp from AGA individuals for the presence of hair follicle stem and progenitor cells. Cells expressing cytokeratin15 (KRT15), CD200, CD34, and integrin, $\alpha 6$ (ITGA6) were quantitated via flow cytometry. High levels of KRT15 expression correlated with stem cell properties of small cell size and quiescence. These KRT15 ${ }^{\text {hi }}$ stem cells were maintained in bald scalp samples. However, CD200 ${ }^{\text {hi ITGA6 }}{ }^{\text {hi }}$ and CD34 ${ }^{\text {hi }}$ cell populations - which both possessed a progenitor phenotype, in that they localized closely to the stem cell-rich bulge area but were larger and more proliferative than the KRT15 ${ }^{\text {hi }}$ stem cells - were markedly diminished. In functional assays, analogous $\mathrm{CD}^{200}{ }^{\mathrm{hi}}$ Itga $6^{\mathrm{hi}}$ cells from murine hair follicles were multipotent and generated new hair follicles in skin reconstitution assays. These findings support the notion that a defect in conversion of hair follicle stem cells to progenitor cells plays a role in the pathogenesis of AGA.
\end{abstract}

\section{Introduction}

Adult somatic stem cells act as the ultimate source of cells for selfrenewing epithelia during homeostasis and wound healing. In the skin, a portion of the hair follicle known as the bulge contains a reservoir of small quiescent stem cells that divide during the onset of each new hair growth cycle or in response to wounding (1-4). Here, we address whether bald scalp in androgenetic alopecia (AGA; also referred to as male pattern baldness) lacks hair follicle stem or progenitor cells.

In AGA, large terminal follicles diminish in size with time, and the resulting miniaturized follicle eventually produces a microscopic hair. Miniaturization of the follicle takes place as the hair follicle cycles. All follicles continuously cycle from a growing stage (anagen), to an involutional stage (catagen), and then to a resting stage (telogen), before again entering anagen (5). In AGA, the new lower hair follicle that forms at anagen onset is smaller than its predecessor. Testosterone is necessary for miniaturization, and 5 - $\alpha$-reductase type II inhibitors, which block conversion of testosterone to its more active form, dihydrotestosterone, delay progression of AGA (6). Little else is understood about the cause of AGA.

Stem cells responsible for hair follicle cycling reside in the hair follicle bulge of both mouse and human skin $(7,8)$. Bulge cells generate all the epithelial lineages within the follicle (9), and their selective destruction leads to loss of the follicle (2). Isolated murine bulge cells, when combined with neonatal dermal cells in a skin reconstitution assay, re-form the entire

Conflict of interest: The authors have declared that no conflict of interest exists. Citation for this article: J Clin Invest. 2011;121(2):613-622. doi:10.1172/JCI44478. cutaneous epithelium, including hair follicle, epidermis, and sebaceous gland $(9,10)$. Bulge cells give rise to a progenitor population called the secondary germ cells, which reside adjacent to the bulge during telogen and produce the new hair shaft at anagen onset. A new secondary germ regenerates from the bulge with each new hair cycle $(1,11)$.

Human hair follicle bulge cells possess stem cell characteristics similar to those of mouse bulge cells. Proliferation studies on mouse skin and on human scalp grafted to immunodeficient mice localize quiescent cells to the bulge $(3,12)$. Gene expression profiles from isolated mouse bulge cells and microdissected human bulge cells share similar patterns $(4,9,13)$. However, to our knowledge no human hair follicle cells have been reported to form hair follicles in reconstitution assays, likely because of limitations of the xenograft system. In vitro proliferation assays indicate that basal bulge cells possess a high proliferative potential consistent with a stem cell phenotype $(13,14)$.

Global gene expression studies of isolated bulge cells from both mice and humans indicate preferential expression of the intermediate filament protein KRT15 and the cell surface marker CD200 $(9,13)$. CD34 expression marks hair follicle bulge cells in mouse, but not human, epithelium $(7,15)$. In humans, CD34 expression is confined to cells immediately below the bulge in the outer root sheath of the anagen hair follicle $(7,14,16)$. These cells undergo apoptosis at the end of anagen, but cells from here form high numbers of colonies in in vitro assays and are considered to be a progenitor population derived from the bulge $(14,17)$. Thus, the use of these markers allows for assessment of stem and progenitor cell populations in human scalp. 

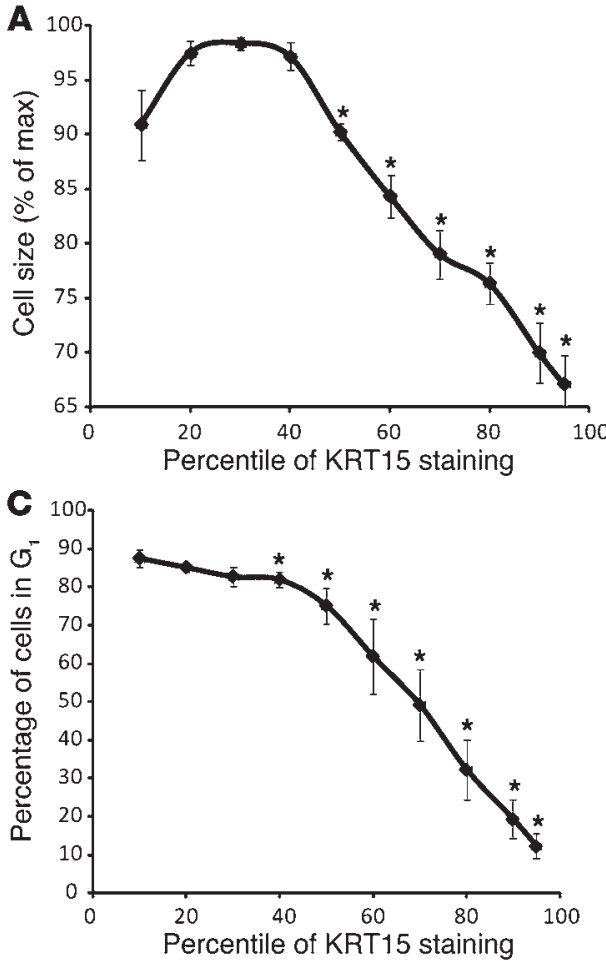

B

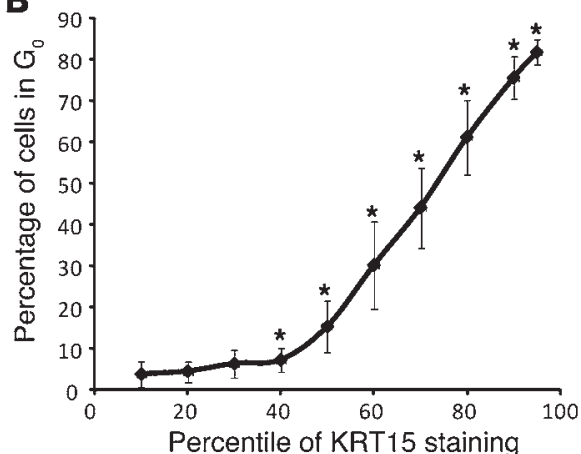

D

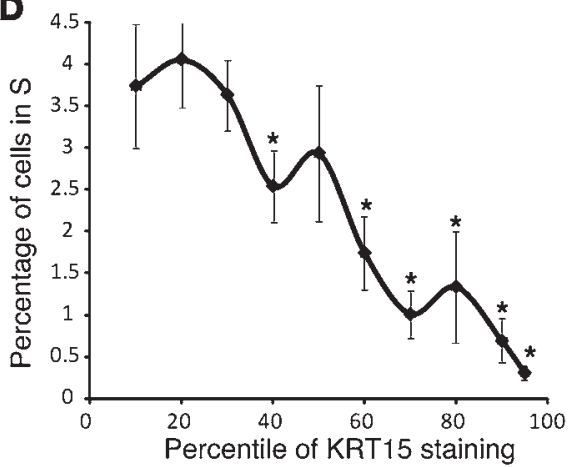

Figure 1

KRT15 expression levels define a gradient of stem cell characteristics in isolated scalp keratinocytes. (A) Using flow cytometry analysis, basal layer $\left(\mathrm{ITGA6}{ }^{+}\right)$cells at the indicated percentiles of KRT15 staining intensity were plotted against their cell size. Increasing levels of KRT15 correlated with smaller cell size $(n=5, P=0.002$ to $\left.P=1.58 \times 10^{-5}\right)$. (B-D) Cell cycle analyses of cells expressing different levels of KRT15. Increasing levels of KRT15 correlated with quiescence. Cells at the 95th percentile for KRT15 expression were predominantly in $\mathrm{G}_{0}(\mathrm{~B} ; n=5$, $P=3.85 \times 10^{-5}$ ), whereas cells at the 10th percentile were predominantly in $\mathrm{G}_{1}\left(\mathbf{C} ; n=5, P=3.1 \times 10^{-5}\right)$ and $\mathrm{S}(\mathbf{D}$; $n=5, P=0.0003) .{ }^{*} P<0.05$.
Here we analyzed KRT15, CD200, and CD34 expression with flow cytometry to assess the stem and progenitor cell compartments in bald and haired (i.e., non-bald) scalp from individuals with AGA. Surprisingly, we found that the stem cell population was maintained in bald scalp. However, CD200 ${ }^{\text {hi ITGA6 }}{ }^{\text {hi }}$ and CD34hi cells were greatly diminished. These lost cells likely represent early progeny of stem cells, based on their position in the follicle, stem cell marker expression levels, cell size, and cell cycle state. Functionally, an analogous murine CD200hi Itga6 $6^{\text {hi }}$ population was capable of regenerating an entire hair follicle, consistent with a progenitor cell phenotype. These results suggest that loss of progenitor cells, but not stem cells, contributes to human male pattern baldness.

\section{Results}

KRT15 expression levels correlate with epithelial stem cell characteristics of small cell size and cell cycle quiescence. To evaluate changes in hair follicle stem cell numbers in human scalp, we used KRT15 expression as a stem cell marker. We focused on cells in the top 5\% of KRT15 expression (KRT15 hi) by flow cytometry, since KRT15 is expressed at the highest levels in bulge cells $(3,14)$. To further verify that KRT15 ${ }^{\text {hi }}$ cells possess epithelial stem cell properties, we analyzed the relationship of KRT15 expression to the known stem cell characteristics of quiescence and cell size $(12,17)$.

Small cell size has been associated with stem cells in multiple tissues (17-19). In epithelia, early studies indicated that small human epidermal keratinocytes were clonogenic and had the greatest proliferative potential (17). More recent analysis confirmed that cells isolated from the bulge are small in size and are highly proliferative in vitro, consistent with their role as stem cells (14). Small corneal epithelial cells also exhibit the highest proliferative potential (19). Finally, cell size may regulate cell cycle progression, since large cell size triggers proliferation (20).
Quiescence remains a defining characteristic of epithelial stem cells in the skin and other tissues $(11,21,22)$. Functional assays demonstrate that quiescent epidermal cells possess the greatest proliferative potential $(9,10)$. Label-retaining cell $(4,7)$, lineage (9), and cell ablation studies (2) confirm that quiescent keratinocytes in the bulge are responsible for constant regeneration of the hair follicle. Human basal bulge cells also retain label and have a quiescent proliferative profile $(3,23)$.

To assess the relationship between KRT15 expression and the stem cell properties of quiescence and small cell size, we measured the cell size and cell cycle characteristics of KRT15-expressing keratinocytes from human adult scalp. We analyzed viable keratinocytes for expression of ITGA6, KRT15, and Ki67 by flow cytometry. The gating strategy is listed in Supplemental Figure 1, A-G (supplemental material available online with this article; doi:10.1172/JCI44478DS1). Cells of increasing percentile of staining for KRT15 were measured to detect cell size by forward scatter (Figure 1A). Cells at the 50th percentile and higher of KRT15 staining were significantly smaller than cells at the 20th percentile $\left(n=5, P=0.002\right.$ to $\left.P=1.58 \times 10^{-5}\right)$. KRT15 expression positively correlated with small cell size: cells expressing the highest levels of KRT15 were smallest (Figure 1A).

To determine cell cycle attributes of cells expressing different levels of KRT15, we used flow cytometry to analyze Ki67 expression and DNA content (Figure 1, B-D, and Supplemental Figure 1, $\mathrm{H}-\mathrm{J})$. We compared cells at increasing percentiles of KRT15 staining with those at the 20 th percentile. The percentage of cells in $\mathrm{G}_{0}$ significantly increased at the 40th and higher percentiles of KRT15 staining (Figure $1 \mathrm{~B} ; n=5, P=0.05$ to $P=3.85 \times 10^{-5}$ ). The percentage of proliferative, $\mathrm{Ki}^{+} 7^{+}$cells was lowest for cells at the 95 th percentile of KRT15 expression: $82 \% \pm 3 \%$ of these cells were in $\mathrm{G}_{0}$, with $12 \% \pm 3 \%$ in $\mathrm{G}_{1}, 5 \% \pm 2 \%$ in $\mathrm{G}_{2} / \mathrm{M}$, and $0.3 \% \pm 0.1 \%$ in $\mathrm{S}$ (Figure 1 , 

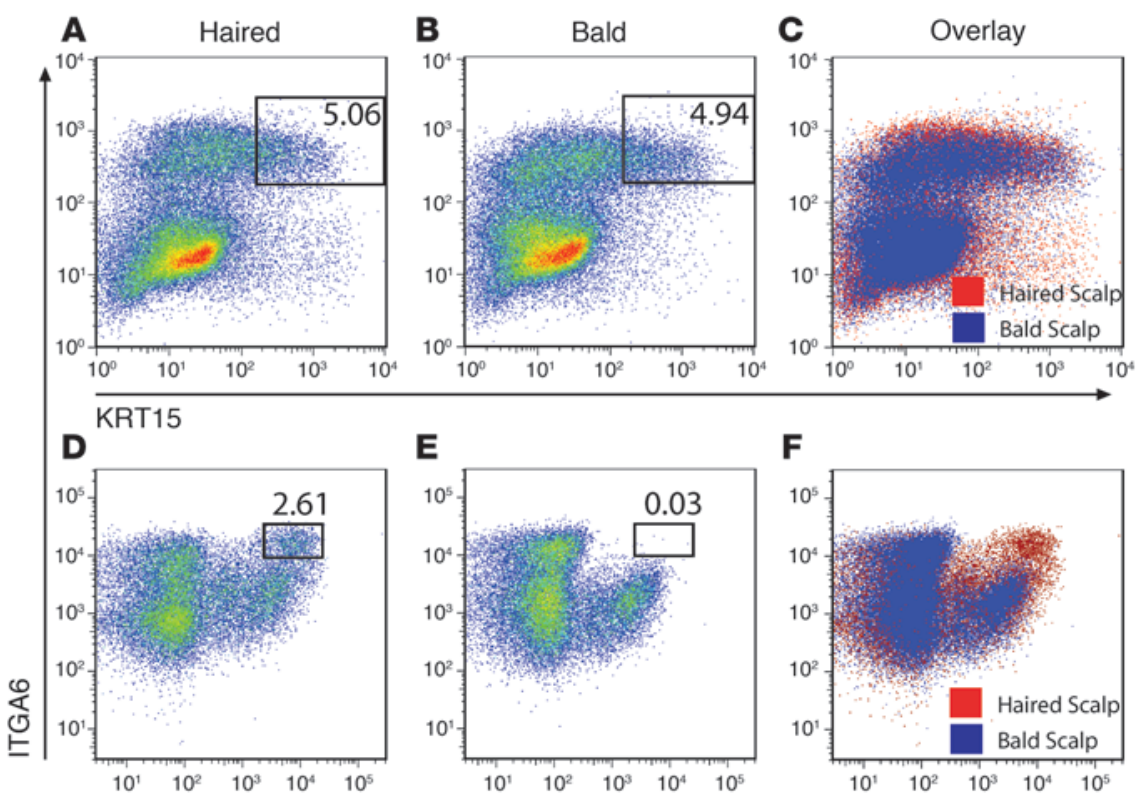

\section{Figure 2}

Preservation of KRT15 hi hair follicle stem cells in bald scalp, but depletion of CD200 hilTGA6 ${ }^{\text {hi }}$ and CD34hi progenitor cells. Pseudocolor dot plots (A, B, D, E, G, and $\mathbf{H}$ ) or overlay graphs (C, $\mathbf{F}$, and I) from FACS analysis of epithelial cells stained with the indicated antibodies. Overlay graphs are plotted first with cells from haired scalp, then layered over with cells from bald scalp. (A-C) Representative example showing KRT15i cells preserved in bald scalp $(n=8, P=0.3)$. In contrast, a defined population of CD200 ${ }^{\text {hi }}$ TTGA6 ${ }^{\text {hi }}$ cells $(\mathbf{D}-\mathbf{F}$;

\section{E}

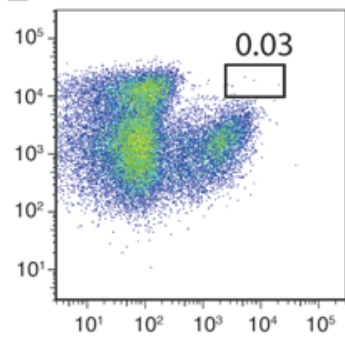

\section{$\mathbf{F}$}

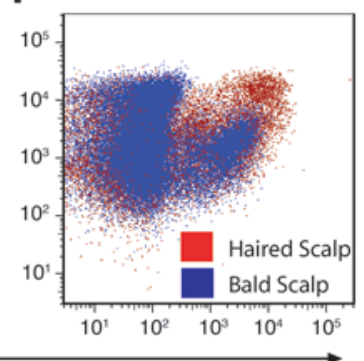
$n=9, P=0.005)$ and CD34 ${ }^{\text {hi }}$ cells (G-I; $n=3, P=0.011$ ) were depleted in bald scalp. Numerical values represent percent cells in the gated population, of all cells plotted in the representative experiments.

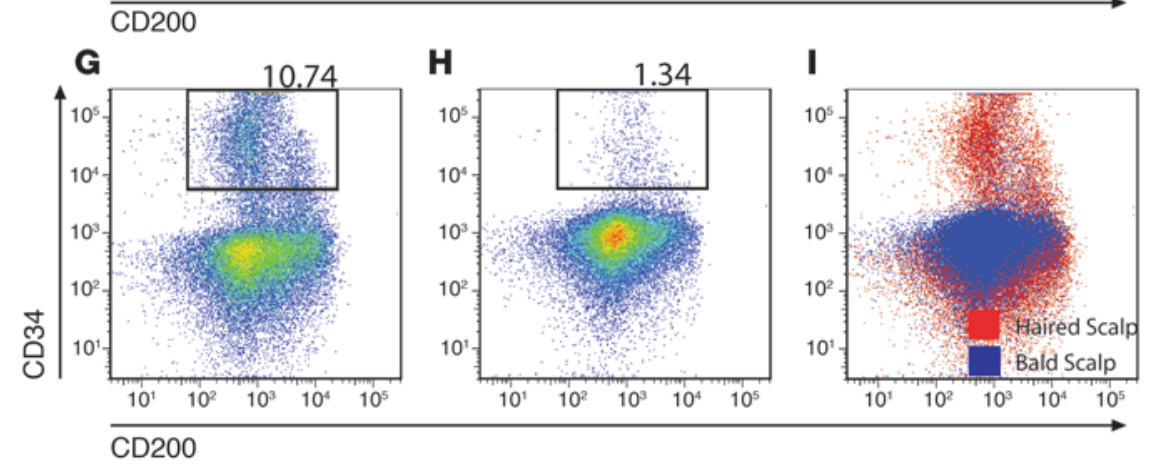

B-D). Coincident with the increase in the percentage of cells in $\mathrm{G}_{0}$, there was a decrease in cells in $\mathrm{G}_{1}$, which indicated that most cells not in $G_{0}$ were instead in $G_{1}$. The percentage of cells in $G_{1}$ was significantly decreased at the higher percentiles (Figure $1 \mathrm{C} ; n=5$, $P=0.05$ to $\left.P=3.1 \times 10^{-5}\right)$. Similarly, cells expressing high levels of KRT15 were less likely to be in S phase (Figure $1 \mathrm{D} ; n=5, P=0.04$ to $P=0.0003) . G_{2} / M$ changes were more variable according to KRT15 levels, as has been published previously (9), but were significantly decreased at the 80th and 90th percentiles (Supplemental Figure $1 \mathrm{~K} ; n=5, P=0.04$ and $P=0.05$ ). Thus, high levels of KRT15 expression correlate well with a quiescent stem cell phenotype.

Bald scalp retains KRT15 $5^{\text {bi }}$ stem cells. Having verified that cells with the highest level of KRT15 expression possess properties of epithelial stem cells, we next addressed whether hair follicle stem cell numbers decrease in bald versus haired scalp from men with AGA. We isolated single-cell suspensions of epithelial cells from bald and haired scalp from the same individuals. These cells were stained with antibodies against ITGA6 and KRT15 and then analyzed by flow cytometry (Figure 2). We defined KRT $15^{\text {hi }}$ cells as those in the top $5 \%$ of staining in haired scalp. In each paired sample from the same individual, an identical gate defining the top $5 \%$ of cells in haired scalp was applied to the cells from bald scalp. The flow cytometry was performed on the same day with identical instrument settings (see Methods for details). On average, the percentage of KRT15 hi cells was the same in bald and haired scalp (Figure 2, A-C; $4.6 \% \pm 0.9 \%$ vs. $5.0 \% \pm 0.02 \%, P=0.3, n=8)$.

Immunohistochemical staining for KRT15 also showed many strongly positive cells in miniaturized follicles from scalp with androgenetic alopecia (Supplemental Figure 2, A and B), which supported the notion that hair follicle stem cells are maintained in bald scalp.

Progenitor cell populations distinct from KRT15 ${ }^{\text {hi }}$ stem cells are depleted in bald scalp. Recently, CD200 expression was identified in human bulge cells in haired scalp from women $(13,14)$. In these studies, the $\mathrm{CD} 200^{+}$population overlapped substantially with the $\mathrm{K} 15^{+}$ population. To define changes in $\mathrm{CD}_{200}{ }^{+}$cells in men with AGA, we analyzed CD200 expression together with expression of the epithelial basal cell marker ITGA6 by flow cytometry in matched bald and haired scalp. We excluded $\mathrm{CD} 45^{+}$hematopoietic cells and $\mathrm{CD} 117^{+}$melanocytes from the starting population and confirmed that the $\mathrm{CD}_{200}{ }^{+}$cells were negative for these nonepithelial markers (Supplemental Figure 1, L and M).

Surprisingly, we found that a well-demarcated population of cells expressing high levels of both CD200 and ITGA6 was markedly decreased in haired versus bald scalp (Figure 2, D-F; $2.3 \% \pm 0.7 \%$ vs. $0.28 \% \pm 0.1 \%, P=0.005, n=9)$. This population represented $10.0 \% \pm 0.1 \%(n=9)$ of the entire $\mathrm{CD}_{200^{+}}$population; to our knowledge, it has not been studied previously.

To better characterize CD200 ${ }^{\text {hiITGA6 }}{ }^{\text {hi }}$ cells with respect to their stem cell properties, we determined their level of KRT15 expres- 

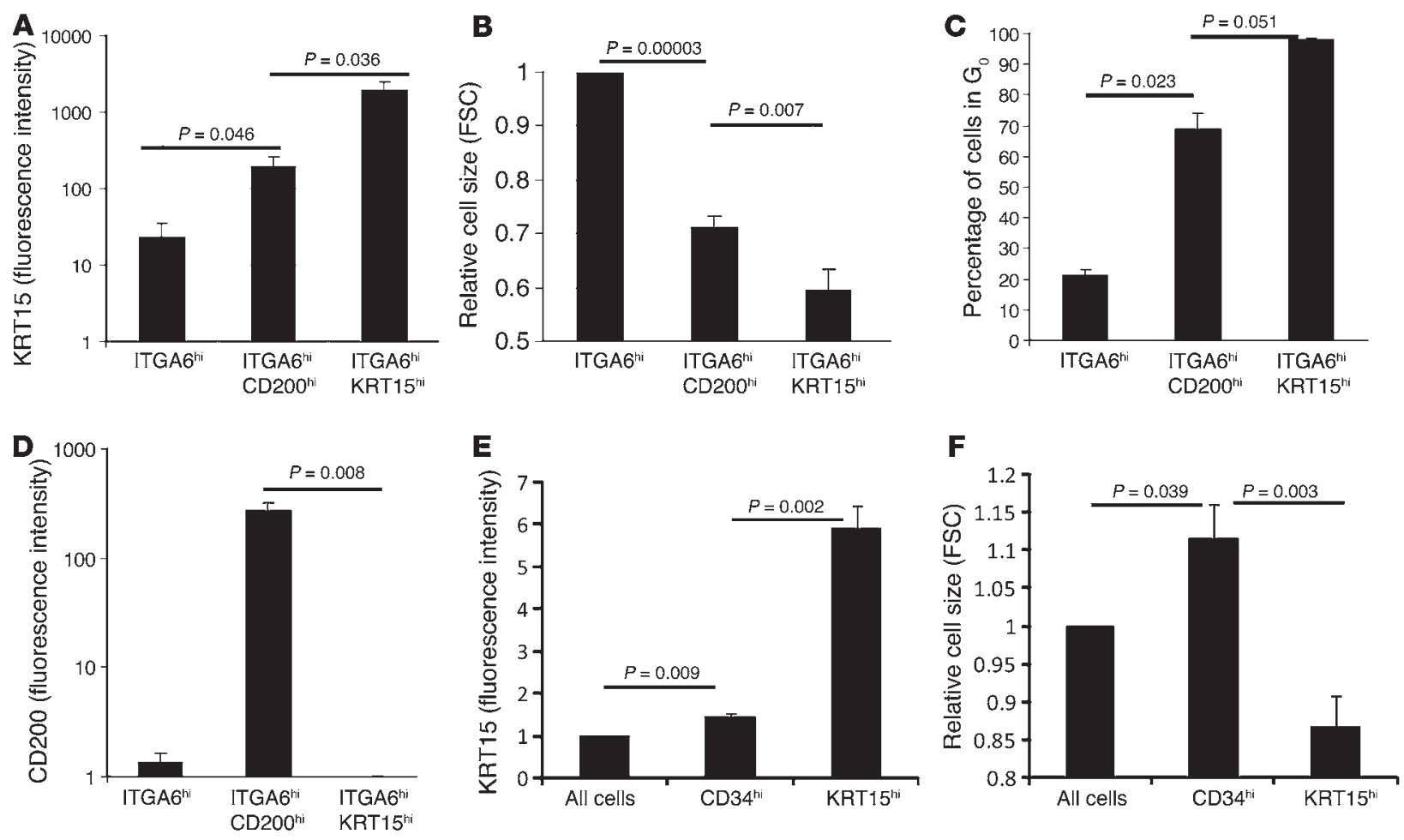

Figure 3

CD200 hilTGA6 ${ }^{\text {hi }}$ and CD34hi cells are distinct from KRT15 hi stem cells and possess a progenitor cell phenotype. (A-C) CD200hilTGA6 ${ }^{\text {hi }}$ cells were intermediate in KRT15 levels $(\mathbf{A} ; n=3)$, cell size $(\mathbf{B} ; n=6)$, and percent of cells in $\mathrm{G}_{0}(\mathbf{C} ; n=2)$ compared with all basal-layer keratinocytes and with KRT15 ${ }^{\text {hi }}$ cells. (D) As an indication of their distinct identities, the majority of KRT15 ${ }^{\text {hi }}$ cells expressed almost no CD200 $(n=3)$. $(\mathbf{E}$ and $\mathbf{F}) \mathrm{CD}_{3} 4^{\text {hi }}$ cells expressed low levels of KRT15 $(\mathbf{E} ; n=4)$ and were larger than KRT15 hi cells $(\mathbf{F} ; n=4)$. FSC, forward scatter.

sion, cell size, and degree of quiescence. We compared cells gated as CD200 ${ }^{\text {hiTGA6 }}{ }^{\text {hi }}$ (Figure 2D), as well as cells gated as KRT15 hi ITGA6 ${ }^{\text {hi }}$ (Figure 2A), with an otherwise ungated population of all ITGA6 ${ }^{\text {hi }}$ cells (Supplemental Figure 1E). CD200hi ITGA6 ${ }^{\text {hi }}$ cells expressed lower levels of KRT15 compared with KRT15 ${ }^{\text {hi }}$ cells $(n=3, P=0.036)$, and higher levels of KRT15 $(n=3, P=0.046)$ compared with ITGA6 ${ }^{\text {hi }}$ cells (Figure $3 \mathrm{~A}$ ). In line with this, we found almost no CD200 expression among the KRT15 hi cells (Figure $3 \mathrm{D} ; n=3, P=0.008)$, which indicates that these populations are distinct. Given the intermediate expression of KRT15 in the CD200hiTGA6 ${ }^{\text {hi }}$ cells, the gradient of stem cell characteristics (Figure 1) predicts that these cells would be intermediate in cell size and cell cycle; indeed, this was the case (Figure 3, B and C). CD200hiTGA6 ${ }^{\text {hi }}$ cells were $75 \% \pm 2 \%$ as large as all ITGA6 ${ }^{+}$cells (Figure 3B; $n=6, P=3 \times 10^{-5}$ ), but were significantly larger than the KRT15 hi cells $(n=6, P=0.007)$. Thus, CD200hiTGA6 ${ }^{\text {hi }}$ cells were of intermediate size compared with the KRT15 ${ }^{\text {hi }}$ cells.

To determine the level of quiescence of the CD200 ${ }^{\text {hiTGA }} 6^{\text {hi }}$ cells, we performed cell cycle analysis. The CD200hiTGA6 hi population showed $69 \% \pm 5 \%$ of cells in $\mathrm{G}_{0}$ (Figure $3 \mathrm{C} ; n=2$ ), significantly higher than all basal cells $(21 \% \pm 1.9 \%, P=0.02)$, but lower than the percentage of KRT $15^{\text {hi }}$ cells in $\mathrm{G}_{0}(98 \% \pm 0.6 \%, P=0.05)$. Thus, CD200 ${ }^{\text {hi ITGA }} 6^{\text {hi }}$ cells were of intermediate size and quiescence compared with KRT15 hi cells.

To assess whether other progenitor cell populations were depleted in bald scalp, we quantitated the number of CD $34^{+}$cells, which juxtapose the bulge and localize below it in the outer root sheath.
We found that $\mathrm{CD} 34^{+}$cells were diminished roughly 10 -fold in bald versus haired scalp (Figure 2, G-I; $1.9 \% \pm 1 \%$ vs. $10.5 \% \pm 0.3 \%$, $P=0.01, n=3) . \mathrm{CD}^{2} 4^{+}$cells expressed low levels of KRT15 and were larger than the KRT15 ${ }^{\text {hi }}$ stem cells (Figure 3, E and F). These findings are consistent with a role for these cells as progenitors descendent from the bulge cells (14).

Human CD200 ${ }^{\text {bi ITGA }} 6^{\text {bi }}$ cells localize to the hair follicle bulge and to the secondary germ. To better localize the CD200hiTGA6 ${ }^{\text {hi }}$ cells that were depleted in bald scalp, we isolated these cells from haired scalp and analyzed them for expression of markers from different compartments of the hair follicle (Figure 4). In addition to KRT15, we used follistatin (FST) as a bulge cell marker (13). The majority of CD200 ${ }^{\text {hi }}$ ITGA6 ${ }^{\text {hi }}$ cells were positive for both KRT15 and FST (Figure 4, B and C). However, approximately $15 \%$ were negative, which indicates that this portion resides outside of the bulge.

To further define the location of the CD200hiTGA6 ${ }^{\text {hi }}$ cells that did not localize to the bulge, we used the Ber-EP4 antibody, which detects epithelial cell adhesion molecule (EPCAM), to stain for secondary germ cells (Figure 4, D-F, Supplemental Figure 3, A and B, and ref. 24). Of the CD200 ${ }^{\text {hi }}$ TGA $6^{\text {hi }}$ cells, $16 \%$ were positive for BerEP4 (Figure 4F), indicative of their localization to the secondary germ. By immunohistochemistry, we detected CD200 expression in the bulge region and in secondary germ cells in telogen human hair follicles from haired scalp (Figure 4E and Supplemental Figure 4 , D and E). In agreement with our fluorescence-activated cell sorting (FACS) analysis, we found a qualitative decrease in staining for $\mathrm{CD}^{200^{+}}$cells in bald scalp (Supplemental Figure 2, C and D). 
A

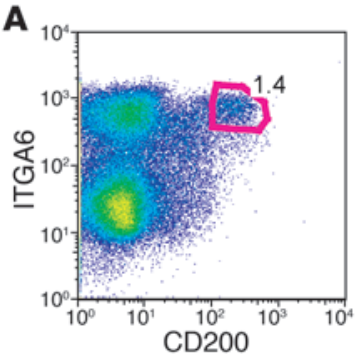

D

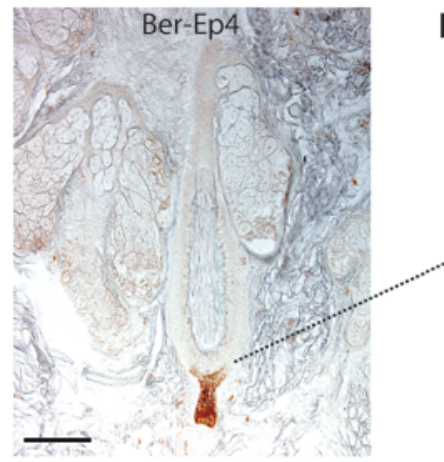

B

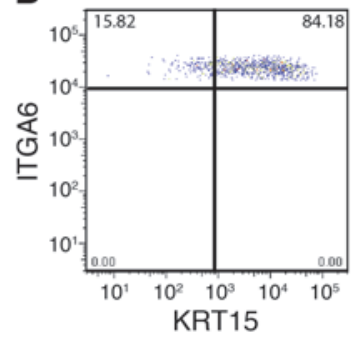

E
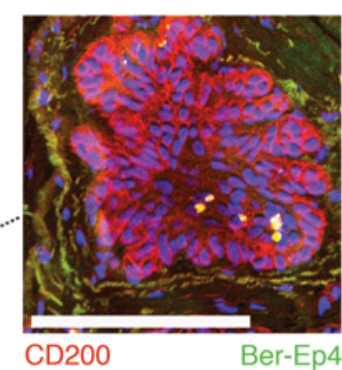

Secondary hair germ Ber-Ep4 ${ }^{\text {dim }}$, CD200* (level above DP)
C
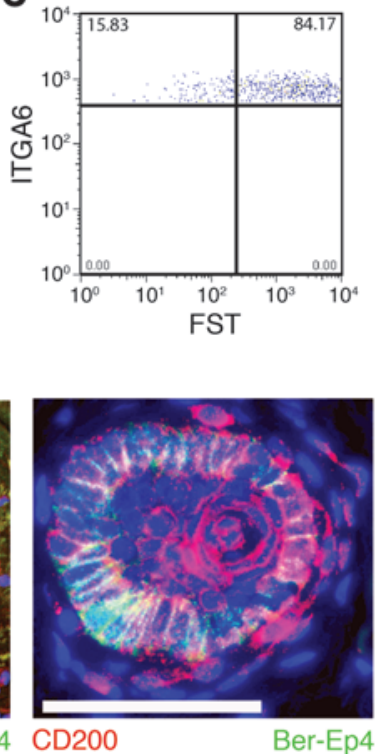

Secondary hair germ: Ber-Ep4 $4^{\text {oright }}$, CD200 (level at DP)
F

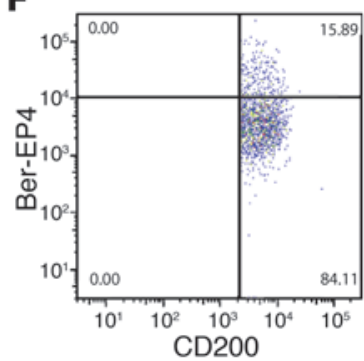

G

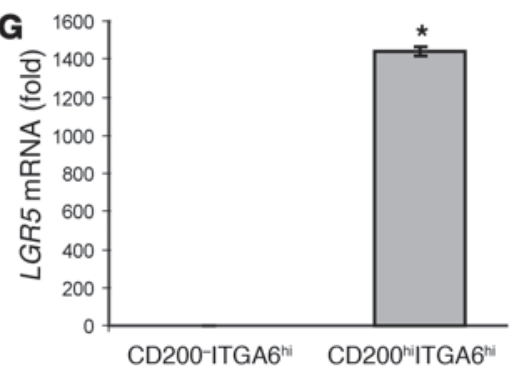

H

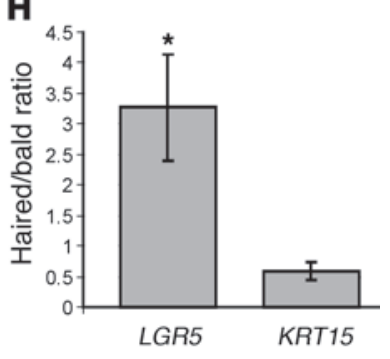

\section{Figure 4}

CD200hilTGA6 ${ }^{\text {hi }}$ cells localize to the hair follicle bulge and to the secondary germ. (A) Gated population of CD200hilTGA6 ${ }^{\text {hi }}$ used for analysis in B, C, F, and G. (B and $\mathbf{C})$ The majority of CD200+ cells were positive for the bulge markers KRT15 (B) and FST (C). (D-F) Ber-EP4 expression marked the secondary germ (D), and CD200 expression overlapped with Ber-Ep4 by double immunofluorescence (E) and flow cytometry (F). (E) Higher numbers of $\mathrm{CD}^{2} \mathrm{OO}^{+}$cells were present in the upper (left) than in the lower (right) secondary hair germ. (G) As assessed by qPCR, sorted CD200 hilTGA6 hi cells were enriched in LGR5, a marker for activated bulge/secondary hair germ cells $(n=3)$. (H) Consistent with this enrichment, LGR5 expression was markedly reduced in bald scalp, whereas KRT15 was maintained, when tested by qPCR $(n=4) .{ }^{*} P<0.01$. Scale bars: $100 \mu \mathrm{m}$. Numbers within dot plots indicate percent cells in the respective gate or quadrant.
To further investigate the relationship of CD200hiTGA6 ${ }^{\text {hi }}$ cells to the secondary germ cells, we evaluated expression of $L G R 5$ by quantitative PCR (qPCR). LGR5 recently has been touted as a marker of hair follicle progenitor cells in the lower bulge and secondary germ (11, 25). We found $L G R 5$ mRNA elevated 1,443 -fold in CD200 ${ }^{\text {hi }}$ ITGA6 $6^{\text {hi }}$ versus CD200-ITGA6 ${ }^{\text {hi }}$ cells (Figure 4G; $n=3, P<0.01$ ).

As another test of the hypothesis that loss of the CD200 ${ }^{\text {hi ITGA }}{ }^{\text {hi }}$ population in AGA represents a loss of activated bulge cells, but not quiescent bulge cells, we compared changes in LGR5 and KRT15 mRNA levels in haired and bald scalp using qPCR (Figure $4 \mathrm{H})$. Loss of epithelial cells expressing LGR5 and KRT15 in bald scalp would result in a haired/bald ratio of gene expression greater than 1 . The haired/bald ratio of KRT15 mRNA was $0.58 \pm 0.14$, indicating at least proportional, if not absolute, maintenance of signal in miniaturized hair follicles (Supplemental Figure 5). However, the ratio of haired to bald scalp mRNA for $L G R 5$ was significantly elevated at $3.3 \pm 0.87$ (Figure $4 \mathrm{H} ; n=4, P<0.01$ ), indicative of a loss of LGR5 mRNA in bald scalp. The enrichment of LGR5 in the CD200hiTGA6 ${ }^{\text {hi }}$ population and the loss of LGR5 in bald scalp underscores that the decrease of CD200hiTGA6 $6^{\text {hi }}$ cells in bald scalp is not simply due to downregulation of CD200 expression, but rather to loss of these cells.

Mouse CD200 ${ }^{\text {hi Itga }} 6^{\text {hi }}$ cells localize to the hair follicle bulge and secondary germ. To enable functional studies of the CD200 hiTGA6 ${ }^{\text {hi }}$ cells, we sought to define an analogous cell population in the mouse hair follicle. In mice, CD200hi Itga $6^{\text {hi }}$ cells accounted for approximately $8 \%$ of the total viable epithelial cell population from back skin (Figure 5C and Supplemental Figure 6). To localize these cells, we took advantage of the known specific expression of CD34 by hair follicle bulge cells in the mouse epithelium (15) and compared CD34 and CD200 staining patterns. Immunostaining demonstrated overlap of their expression in the bulge, but extension of CD200 staining into the CD34- secondary germ (Figure 5, A and B, and Supplemental Figure 3C). By FACS analysis, approximately $82 \%$ of the $\mathrm{CD} 200^{\text {hi Itga }} 6^{\text {hi }}$ cells were $\mathrm{CD} 34^{+}$and therefore localized to the bulge (Figure 5F). Together with the immunostaining data, these results indicate that roughly $18 \%$ of CD200hi Itga $6^{\text {hi }}$ cells localized to the secondary germ. This corresponds closely to the $15 \%$ of human CD200 ${ }^{\text {hiTGA }}{ }^{\text {hi }}$ cells that localized to the secondary germ based on their Ber-EP4 ${ }^{\text {hi }}$ status (Figure 4F). Thus, the mouse and human CD200 ${ }^{\text {hi ITGA }} 6^{\text {hi }}$ populations localize to both bulge and secondary germ in equivalent ratios.

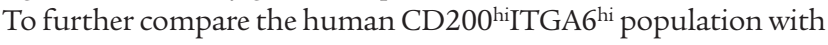
mouse CD200 $0^{\text {hi Itga }} 6^{\text {hi }}$ cells, we performed cell cycle analysis of the mouse as we did on human CD200 ${ }^{\text {hi }}$ ITGA6 $6^{\text {hi }}$ cells (Figure 3). Specifically, we compared cell cycle features in mouse bulge $\left(\mathrm{CD} 200^{+} \mathrm{CD} 34^{+}\right)$ and secondary hair germ $\left(\mathrm{CD} 200^{+} \mathrm{CD} 34^{-}\right)$cells (Figure $\left.5 \mathrm{G}\right)$ with the human CD200hitTGA6 ${ }^{\text {hi }}$ population (Figure 3). 
A

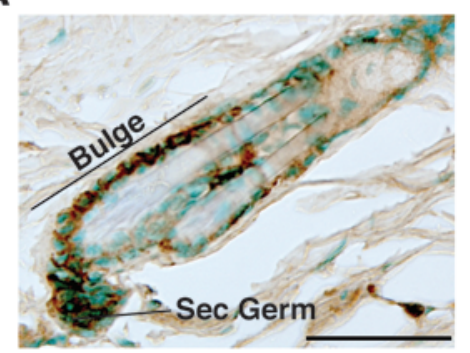

B

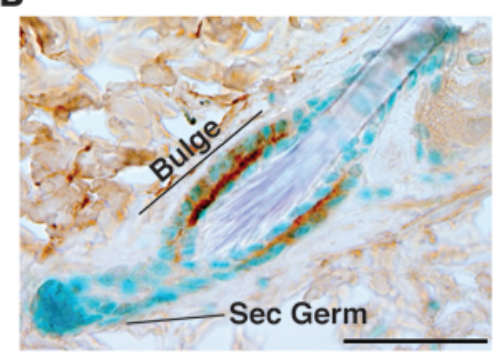

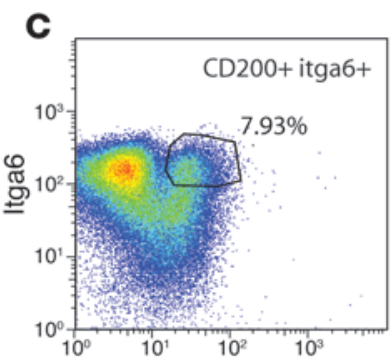

CD200

$$
\text { E }
$$

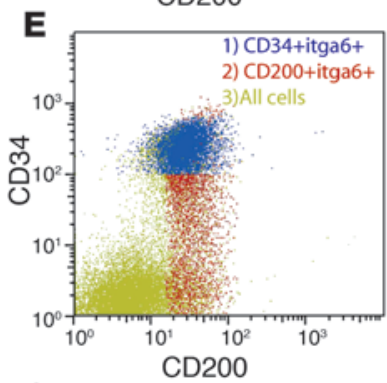

G

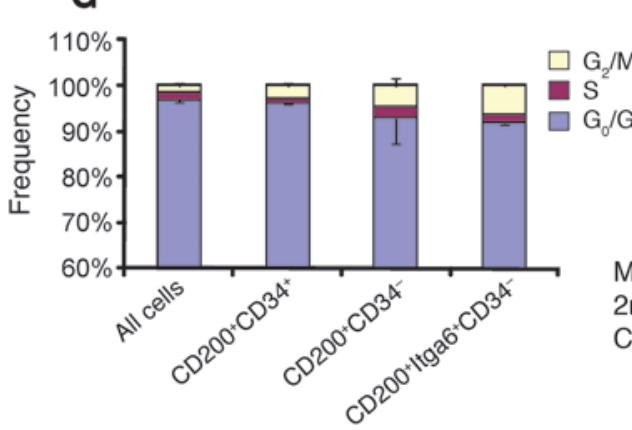

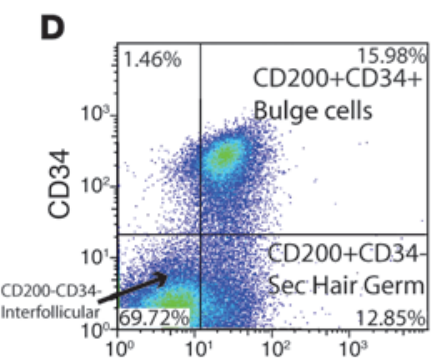

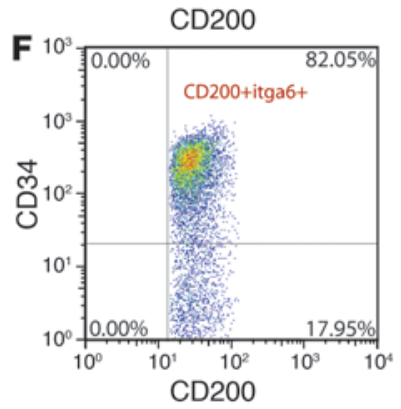

H Gene expression overlap ( $n$ )

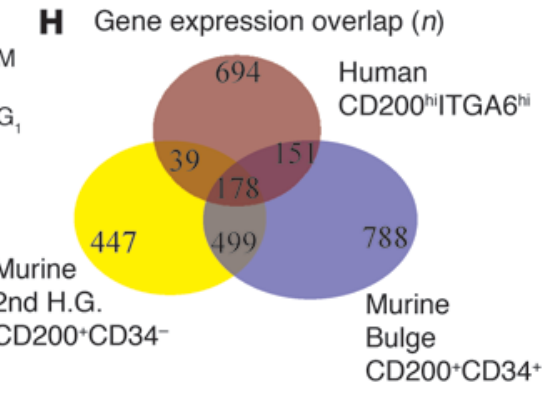

\section{Figure 5}

Mouse CD200 hiltga6 ${ }^{\text {hi }}$ cell location, cell cycle status, and gene expression are similar to those of human CD200hilTGA66i cells. (A and B) As assessed by immunohistology of mouse skin, CD200 was expressed in bulge and secondary hair germ cells (A), whereas CD34 was expressed in bulge cells, but not secondary hair germ cells (B). (C) FACS identified a CD200 ${ }^{\text {hiltga }} 6^{\text {hi }}$ population. (D) CD200 versus CD34 identified bulge cells (CD200 ${ }^{\text {hiCD34+ }}$ ) and secondary hair germ cells $\left(C D 200^{\text {hi }}{ } D 34^{-}\right)$. (E) CD34 ${ }^{\text {hiltga6 }} 6^{\text {hi }}$ cells (Supplemental Figure 6 E) overlaying CD200 hiltga6 ${ }^{\text {hi }}$ cells (as in C) demonstrated that CD200 ${ }^{\text {hiltga }} 6^{\text {hi }}$ cells extended to a CD34- population, but CD34 hiltga6 ${ }^{\text {hi }}$ cells were entirely CD200+. In $\mathbf{F}$, only the CD200 hiltga6 ${ }^{\text {hi }}$ population is shown, exhibiting overlap to the secondary hair germ. (G) Cell cycle analysis demonstrated the lowest frequency of $G_{0} / G_{1}$ in CD200 hiltga6 ${ }^{\text {hi }}$ cells in the secondary hair germ (CD34-; $n=3, P=0.02$ ). (H) Enriched gene lists from microarray expression analysis of human CD200 $0^{\text {hilTGA }}{ }^{\text {hi }}$, mouse bulge (CD200 hi CD34+), and mouse secondary hair germ $\left(C D 200^{\text {hi }}\right.$ CD34-) cells demonstrated that the human CD200 $0^{\text {hilTGA6 }} 6^{\text {hi }}$ population overlapped with both mouse populations, but more so with murine bulge than with murine secondary hair germ. Scale bars: $100 \mu \mathrm{m}$. Numbers within dot plots indicate percent cells in the respective gate or quadrant.
Consistent with previous studies demonstrating quiescence of the bulge cells $(4,9,15)$, the proportion of bulge cells in $S$ phase $(0.84 \% \pm 0.1 \%)$ was significantly lower than in all cells (Figure $5 \mathrm{G} ; 1.44 \% \pm 0.004 \%, n=3, P=0.02$ ). The mouse bulge did show increased numbers of cells in $\mathrm{G}_{2} / \mathrm{M}$ (all cells $1.46 \% \pm 0.5 \%$, bulge cells $2.84 \% \pm 0.5 \%, P=0.02$ ), as described previously (9). The $4.44 \% \pm 1.5 \%$ of secondary germ cells $\left(\mathrm{CD}^{2} 4^{-}\right)$in $\mathrm{G}_{2} / \mathrm{M}$ was higher than that of the bulge (26). The cells demonstrating the highest percentage of $\mathrm{G}_{2} / \mathrm{M}$ were $\mathrm{CD} 200^{\text {hi Itga }} 6^{\text {hi }}$ in the secondary hair germ (Figure 5G; 6.07\% $\pm 0.3 \%, n=3, P=0.01$ ).

In an inverse pattern, the percentage of cells in $G_{1} / G_{0}$ was decreased in cells with elevated levels of $\mathrm{G}_{2} / \mathrm{M}$. Therefore, $\mathrm{CD} 200^{\text {hi Itga }} 6^{\text {hi }}$ cells of the secondary hair germ showed significantly lower levels of cells in $\mathrm{G}_{1} / \mathrm{G}_{0}(89.5 \% \pm 0.4 \%, n=3)$ than did bulge cells $(95.7 \% \pm 0.2 \%$, $n=3, P=0.02)$. In summary, the decreased proportion of cells in
$\mathrm{G}_{1} / \mathrm{G}_{0}$ in the mouse $\mathrm{CD} 200^{\text {hi }}$ Itga ${ }^{\text {hi }} \mathrm{CD} 34^{-}$population compared with $\mathrm{CD} 34^{+}$bulge cells was similar to our cell cycle analysis demonstrating decreased $\mathrm{G}_{0}$ levels in human CD200 ${ }^{\text {hi }}$ ITGA6 ${ }^{\text {hi }}$ cells compared with KRT15 hi bulge cells (Figure 3 ). We conclude that both mouse and human CD200 ${ }^{\text {hiTGA }} 6^{\text {hi }}$ cells show evidence of cell cycle activation compared with cells of the bulge.

To further compare the mouse and human CD200hiTGA6 ${ }^{\text {hi }}$ cells, we analyzed their global gene expression patterns using microarrays. Given that mouse CD200hiItga6 hi cells were composed of both bulge and secondary hair germ cells (Figure 5, E and F), we compared the expression of human CD200 ${ }^{\text {hi ITGA }} 6^{\text {hi }}$ cells with those of mouse bulge and mouse secondary hair germ in a crossspecies comparison. Gene lists of enriched genes for each population were created (see Methods) and compared for overlap (Figure $5 \mathrm{H})$. Although mouse bulge and mouse secondary hair germ gene 

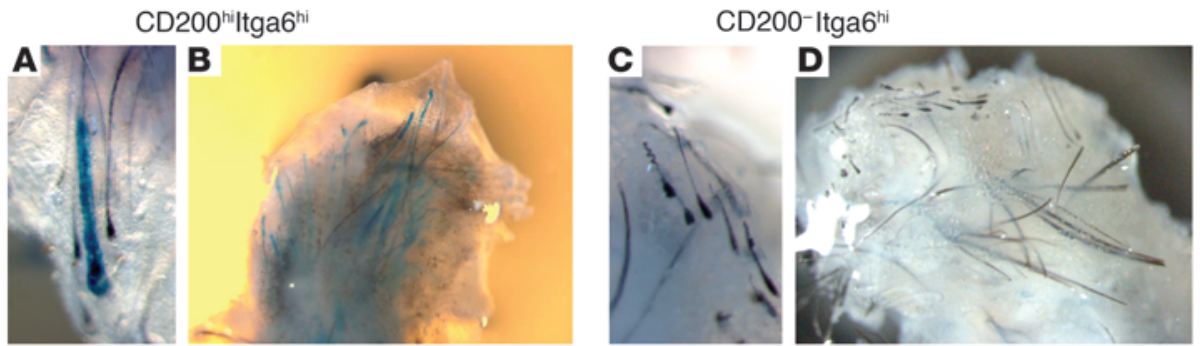

E

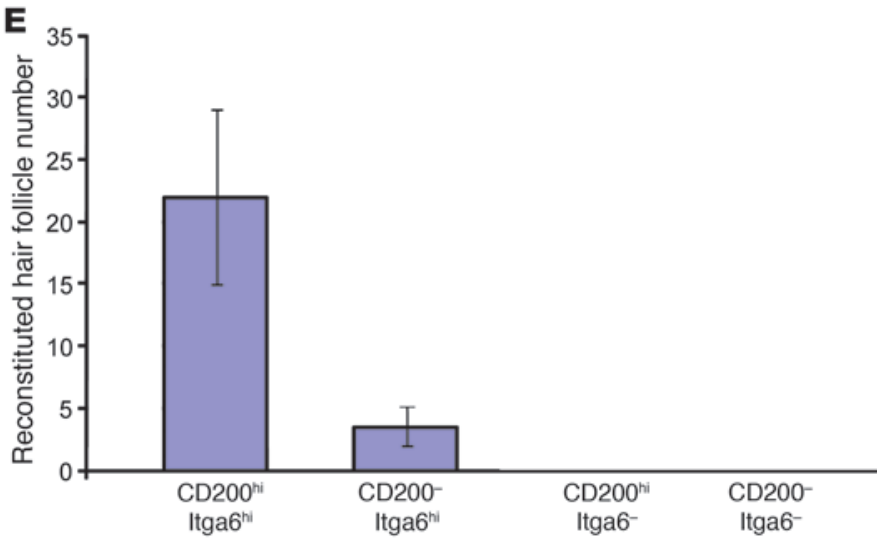

\section{Figure 6}

Mouse CD200 hiltga6 ${ }^{\text {hi }}$ cells are multipotent and capable of reconstituting a hair follicle. (A-D) Stereoscopic images of grossly dissected subcutaneous cysts from SCID mouse hosts after injection of sorted cells isolated from ROSA26 mice that constitutively express $\beta$-galactosidase, which allows for development of blue color. Hair follicle regeneration from injected CD200hiltga6 hi cells (A and $\mathbf{B})$ appeared greater than that from CD200-Itga6 ${ }^{\text {hi }}$ cells (C and D). (E) Quantitation of the number of blue hairs originating from sorted cells demonstrated a greater number of de novo hair follicles in CD200 ${ }^{\text {hiltgaa }} 6^{\text {hi }}$ compared with CD200-ltga6 ${ }^{\text {hi }}$ cells in 2 subsequent independent repeat experiments. expression patterns showed the most overlap (499 genes), it is likely that this is explained by species homogeneity. All 3 populations shared 178 genes. Interestingly, of the populations uniquely shared between the human CD200 ${ }^{\text {hiTGA }} 6^{\text {hi }}$ cells and the mouse cell populations, more genes were shared with mouse bulge ( 151 genes) than with mouse secondary hair germ (39 genes). The greater overlap with the bulge compared with the secondary hair germ matches the cellular composition of the CD200hiTGA6hi populations in both mice and humans. Further analysis of these gene lists (Supplemental Figure 9) showed that shared human and mouse genes present in the bulge were enriched in biologic adhesion proteins, whereas transcripts of the secondary hair germ were enriched in genes regulating death and apoptosis. These results are consistent with the concept that substrate attachment maintains the quiescent phenotype of the bulge cells and that the loss of these adhesions is associated with differentiation to secondary hair germ cells.

Mouse CD200 ${ }^{\text {hi }}$ tga $6^{\text {hi }}$ cells are multipotent and capable of regenerating hair follicles in a skin reconstitution assay. We performed functional analysis on the CD200 ${ }^{\text {hi Itga }} 6^{\text {hi }}$ population using a reconstitution assay, which tests the ability of isolated cell populations to regenerate hair follicles. Isolated single cells from epithelium are combined with neonatal dermal cells and injected intradermally into an immunodeficient mouse host. After 4 weeks, the injected tissue is examined for the presence of newly formed hair follicles, epidermis, and sebaceous glands $(9,27)$.

We sorted CD200 ${ }^{\text {hi Itga }} 6^{\text {hi }}$ or CD200-Itga6 $6^{\text {hi }}$ cells from ROSA26 reporter mice. Grafting of $\mathrm{CD} 200^{\text {hi Itga }} 6^{\text {hi }}$ keratinocytes together with neonatal dermis successfully reconstituted hair follicles (Figure 6, A, B, and E). CD200-Itga6 ${ }^{\text {hi }}$ keratinocytes produced few hair follicles, despite injection of equal numbers of cells (Figure 6, C-E). Contaminating neonatal epidermis from neonatal dermal preparations contributed to some hair follicle formation in both samples (Figure 6, A-D), but could be distinguished by its lack of $\beta$-galactosidase activity. Histologic sectioning of reconstituted hair-bearing cysts demonstrated contribution of CD200hi Itga $6^{\text {hi }}$ cells to all hair follicle lineages, including outer root sheath, inner root sheath, and sebaceous gland (Supplemental Figure 7, A-C), indicative of the multipotency of these cells.

\section{Discussion}

To our knowledge, the status of the hair follicle stem cell compartment in AGA has not been previously addressed. We hypothesized that the miniaturization of the hair follicle seen in AGA may result from loss of hair follicle stem cells. We showed that high levels of KRT15 expression correlated with a stem cell phenotype and found that KRT15 ${ }^{\text {hiTGA }} 6^{\text {hi }}$ stem cells were preserved in bald scalp, whereas distinct populations of CD200 ${ }^{\text {hiTTGA }} 6^{\text {hi }}$ and CD34 ${ }^{\text {hi }}$ cells were markedly diminished. The diminished cell populations likely arise from the KRT15 $15^{\text {hiTGA }} 6^{\text {hi }}$ stem cells, since they were located within or adjacent to the stem cell population and possessed a more activated phenotype. Thus, our findings suggest that AGA results from diminished conversion of hair follicle stem cells to progenitor cells.

Preservation of hair follicle stem cells in AGA. The preservation of KRT15 ${ }^{\text {hiTTGA6 }}{ }^{\text {hi }}$ cells in AGA is consistent with the current clinical concept that AGA is a nonscarring type of alopecia. Dermatologists classify alopecias into scarring and nonscarring categories. Some types of alopecia (e.g., lichen planopilaris, discoid lupus erythematosus, and graft-versus-host disease) are associated with destruction of hair follicle stem cells in the bulge and permanent hair loss. Ablation of the stem cell compartment leading to scarring alopecia has been replicated experimentally in mice through transgene expression of a cytotoxic gene in the bulge (2). In reversible types of alopecia (e.g., alopecia areata), inflammation targets hair follicle progenitor cells but spares hair follicle stem cells. In these disorders, regrowth occurs with suppression of inflammation and subsequent regeneration of the hair follicle from uninjured stem cells (5). Our finding that AGA, in the clinical category 
of nonscarring alopecia, demonstrated preservation of hair follicle stem cells suggests potential reversibility of this condition.

Loss of progenitor cells in AGA. The loss of CD200hiTTGA6 ${ }^{\text {hi }}$ cells and CD34hi cells in AGA provides insights into possible mechanisms leading to follicular miniaturization, the hallmark of AGA. CD200 ${ }^{\text {hi }}$ ITGA $^{\text {hi }}$ cells localized to the bulge and secondary germ, which is present in the telogen follicle. Secondary germ cells arise from the bulge at the end of catagen and are immediately responsible for formation of the new lower hair follicle at anagen onset (1). A decrease in this cell population, possibly due to a lack of replenishment from bulge cells, could potentially result in diminished numbers of bulb matrix cells in the new lower hair follicle. Decreased matrix cell numbers would result in diminutive hair shafts, since these cells are immediately responsible for hair shaft production. The decrease in secondary germ cell numbers in bald scalp is particularly striking, given that bald scalp possesses a greater percentage of telogen follicles and thus should have increased numbers of secondary germ cells compared with haired scalp, which has a higher anagen percentage (28).

The loss of CD34 hi cells from bald scalp is consistent with both a loss of progenitor cells in miniaturized anagen follicles and a decrease in the percentage of anagen follicles in bald scalp. CD34 ${ }^{+}$ epithelial cells are only evident in the outer root sheath of anagen follicles, where they slightly overlap with the bulge cells and continue downward (7). Whether the decrease in these cells is a primary or secondary event in AGA remains to be determined; however, their previously reported high proliferative potential in vitro raises the possibility that they are necessary for generation of large follicles.

Our results using KRT15, CD200, and CD34 to identify stem and progenitor cells in human scalp are supported by recent studies. Inoue et al. used similar markers to identify differences between progenitor and stem populations in scalp (14); their report confirmed the relationship between small cell size and clonogenicity in keratinocytes and also showed that the $\mathrm{CD} 34^{+}$keratinocytes are the most differentiated of the 3 marker populations.

A second recent report demonstrates that $\mathrm{CD}_{200^{+}}$hair follicle stem cells are preserved in chronologic aging of the scalp (29). We demonstrate here that a subset of these cells, the CD200 ${ }^{\text {hi ITGA6 }}{ }^{\text {hi }}$ population, was lost in AGA and was intermediate in the stem cell features of cell size and quiescence compared with the KRT15 hi population and with all cells. Therefore, we speculate that the loss of CD200hiTGA6 $6^{\text {hi }}$ cells reflects the pathologic loss of a daughter population, owing to lack of activation of parent KRT15 hi cells in AGA. Given the capacity of CD200 ${ }^{\text {hi Itga }} 6^{\text {hi }}$ cells to generate multiple lineages of the hair follicle (Figure 6), the lack of these cells might contribute to the miniaturization of the hair follicle during AGA.

Our studies demonstrated heterogeneity of the human hair follicle bulge stem cell area as well as the secondary germ area, findings that we believe to be novel. Although bulge cells as a whole were shown to generate all epithelial cell types in the lower anagen hair follicle of the mouse, prior evidence suggests that subpopulations of cells within the bulge are responsible for generating different segments of the follicle epithelium $(11,26,30)$. Cells from the lower bulge formed the secondary germ, for example $(1,26)$. Our more detailed analysis of the secondary germ delineated further subdivisions within this structure based on proliferative properties. We showed that the human bulge also had subpopulations of cells with differing cell cycle properties that could be recognized by different markers. These insights provide tools for analyzing hair disorders and other skin conditions with respect to their stem and progenitor complement. Understanding the signals responsible for transition of stem cells to progenitor and more differentiated cells will be the next step in developing new treatments for skin disorders.

\section{Methods}

\section{Tissue samples}

This study used only normally discarded human scalp obtained anonymously and was approved by University of Pennsylvania's IRB office as an exempt protocol. Normally discarded human scalp was obtained during hair transplantation. During the hair transplantation procedure, 2-mm-wide by several-centimeter-long specimens are taken from the donor occipital scalp and then dissected into various graft sizes (single hair grafts to multiple hair grafts). Some tissue is deemed unsatisfactory for transplantation, for example, because of inadvertent sectioning. These discarded donor samples from the occipital scalp were used as haired specimens. Likewise, 1.2- $\mathrm{mm}$ and $1.7-\mathrm{mm}$-diameter cylindrical punches are performed to remove bald frontal scalp and create vacant recipient sites for donor scalp. This normally discarded tissue from the frontal scalp was used as the bald samples. Haired and bald samples were taken randomly and included both interfollicular epidermis as well as hair follicles. Tissue was all from white males ranging in age from 40 to 65 years. None of the subjects was using finasteride; 1 subject used minoxidil and was found to have a FACS profile similar to that of the others. Discarded tissue was obtained from a total of 54 males.

All animal protocols were approved by the University of Pennsylvania Institutional Animal Care and Use Committee. ROSA26 and SCID mice were acquired and used as published previously (9).

\section{Immunohistochemistry}

Previously published protocols were followed (20). Briefly, paraformaldehyde-fixed, paraffin-embedded slides containing human scalp hair from excisions were deparaffinized and rehydrated. Microwave antigen retrieval was used with $10 \mathrm{mM}$ citrate buffer ( $\mathrm{pH}$ 6.8). Slides were treated with hydrogen peroxidase to block endogenous HRP activity. Slides were washed and treated with blocking reagent and then primary antibody (mouse anti-KRT15, Lab Vision clone LHKRT1; rat anti-mouse CD34, MEC 14.7; goat anti-human CD200, R\&D Systems; goat anti-mouse CD200, R\&D Systems; and mouse anti-human Ber-EP4, Dako). Secondary biotinylated anti-mouse antibody (Kirkegaard and Perry Laboratories Inc.) and biotinylated anti-goat/rat (Vector) were added following a wash. Slides were again washed, treated with streptavidin-HRP (Vectastain), developed using $\mathrm{ABC}$ kit, and counterstained with Methyl Green (Vectastain). For immunofluorescence, Streptavidin-Texas red or anti-rat FITC (Abcam) were used. Frozen sections were air-dried, washed with PBS, fixed with acetone, washed with PBS, and incubated with the above antibodies, followed by staining as described above. Staining and preparation of $\beta$-galactosidase expressing tissues was performed as previously described (9).

\section{Flow cytometry}

Samples were treated with $5 \mathrm{U} / \mathrm{ml}$ Dispase (Sigma-Aldrich) overnight. The epidermis and dermis were separated, including removal of individual hair shafts, surrounding follicle, and surrounding interfollicular epidermis simultaneously. Isolated epidermis was then washed in PBS and treated with tryp$\sin$ for 15 minutes at $37^{\circ} \mathrm{C}$ in the presence of DNAse. The sample was vortexed and filtered through a $70-\mu \mathrm{m}$ filter. Cells were spun at $200 \mathrm{~g}$ for 5 minutes and counted using a hemocytometer. For every stage of the above procedure, tissue was saved for monitoring of successful purification by hematoxylin and eosin staining. We grossly and histologically verified tissue identity and success of sample preparation (Supplemental Figure 8). Between $0.5 \times 10^{6}$ and $1 \times 10^{6}$ cells were used for counting each sample, with attempts made to quan- 
tify the maximum possible during flow analysis. Unless otherwise indicated, all antibodies used were identical to those used for immunohistochemistry. Samples were stained with various combinations of antibodies to CD200 (MRC OX-104) and ITGA6 (BD Biosciences - Pharmingen clone GoH3), fixed and permeabilized (Caltag labs), and stained with the above anti-human antibodies against actin (Sigma-Aldrich clone AC-15), KRT15, FST, Ki67 (BD Biosciences - Pharmingen clone B56), CD117 (BD Biosciences clone 104D2), CD45 (BD Biosciences clone 2D1), Ber-EP4, DAPI, and/or an isotype control (IgG2a, Sigma-Aldrich). Staining of mouse skin was done as previously described (9). For murine staining, we used anti-mouse CD200 (Serotec OX-90), CD117 (BD Biosciences clone 2B8), and CD45 (BD Biosciences clone 30-F11). Mouse and human staining of CD200 hi ITGA ${ }^{\text {hi }}$ cells was shown to be CD117-CD45- Ki67 antibody required careful titration to limiting amounts of antibody. An alternative method to fixing and permeabilizing cells was incubation in $70 \%$ ethanol for at least 24 hours. Non-prelabeled antibodies were labeled with chromophores preconjugated to Fab (Zenon Tricolor and AF680 IgG2a and Tricolor, AF488 and AF750-APC IgG1 kit). Analyses were performed on a dual-laser flow cytometer (BD FACSCalibur) or a 4-laser 10-color LSR II (BD). All flow cytometry data were analyzed by uploading files into FlowJo 4.6 (TreeStar Inc.). Sorting was performed as previously described (9). Briefly, a FACSVantage machine running Diva software equipped with a $100-\mu \mathrm{m}$ nozzle and low-pressure settings (18-22 psi) was used for cell sorting, using antibodies and gates described in Results. For scalp samples from the same individual, we used identical gating and antibody staining conditions. Note that with the software used for FACS analysis, it was not possible to gate exactly on $5.00 \%$. Thus, manual gating resulted in small variations around $5 \%$ in haired scalp.

For cell cycle analysis, adult scalp keratinocytes from 5 samples from 3 individuals were stained with the DNA dye DAPI to separate diploid $\left(G_{0}\right.$ and $\left.G_{1}\right)$ from tetraploid $\left(\mathrm{M}_{\text {and }} \mathrm{G}_{2}\right.$ ) cells. Intermediate DNA content was interpreted as $S$ phase. To separate $G_{0}$ from $G_{1}$, cells were stained with Ki67; cells with undetectable levels of Ki67 were operationally defined as being in $\mathrm{G}_{0}(31)$.

\section{Quantitative real-time PCR}

Manufacturers' recommended protocols were followed at all steps. Human tissue samples from haired and bald scalp were placed in RNAlater (Qiagen) buffer, stored at $-20^{\circ} \mathrm{C}$, and then homogenized using an Omni TH-01 polytron. Sorted mouse cell or homogenized tissue RNA was extracted from samples using RNeasy (Qiagen) and measured using spectrophotometry, and equal amounts were subjected for cDNA conversion using High Capacity kit (Applied Biosystems). Equal amounts of cDNA were mixed with Taqman Fast Universal PCR Master Mix (Applied Biosystems) and appropriate probe sets. qPCR reactions were run in a StepOne Plus system and analyzed using StepOne Software (Applied Biosystems). Probes used were 00267035 (KRT15), 00437762 ( $\beta$-Actin), and 00173664 (LGR5) from Applied Biosystems.

\section{Expression arrays}

Target preparation and hybridization. Microarray results were based on cells harvested from 3 independent cell sorting dates. For human arrays, cells from the haired scalp of 1 individual were used on each date. For mouse arrays, 3-5 adult mice age 50-60 postnatal days were pooled for each date. RNA was extracted using RNAeasy (Qiagen) kit. All protocols were conducted by the Penn Microarray Core as described in the Affymetrix GeneChip Expression Analysis Technical Manual. Briefly, $5 \mu \mathrm{g}$ total RNA was converted to first-strand cDNA using Superscript II reverse transcriptase primed by a poly $(\mathrm{T})$ oligomer that incorporated the $\mathrm{T} 7$ promoter. Second-strand cDNA synthesis was followed by in vitro transcription for linear amplification of each transcript and incorporation of biotinylated CTP and UTP. The complementary RNA products were fragmented to 200 nucleotides or less, heated at $99^{\circ} \mathrm{C}$ for 5 minutes, and hybridized for 16 hours at $45^{\circ} \mathrm{C}$ to U133A Affymetrix microarray for human and $430 \mathrm{v} 2$ for mouse. The microarrays were then washed at low (6X SSPE) and high (100 $\mathrm{mM} \mathrm{MES}, 0.1 \mathrm{M} \mathrm{NaCl}$ ) stringency and stained with streptavidin-phycoerythrin. Fluorescence was amplified by adding biotinylated anti-streptavidin and an additional aliquot of streptavidin-phycoerythrin stain. A confocal scanner was used to collect fluorescence signal at $3-\mu \mathrm{m}$ resolution after excitation at $570 \mathrm{~nm}$. The average signal from 2 sequential scans was calculated for each microarray feature.

Initial data analysis. Affymetrix GeneChip Operating System (GCOS version 1.4, Affymetrix Inc.) was used to quantitate expression signal levels for the arrays; default values provided by Affymetrix were applied to all analysis parameters. Border pixels were removed, and the average intensity of pixels within the 75 th percentile was computed for each probe. These values were exported as .cel files. The average of the lowest $2 \%$ of probe intensities occurring in each of 16 microarray sectors was set as background and subtracted from all features in that sector. Probe pairs were scored positive or negative for detection of the targeted sequence by comparing signals from the perfect match and mismatch probe features. The number of probe pairs meeting the default discrimination threshold $(\tau=0.015)$ was used to assign a call of absent, present, or marginal for each assayed gene, and a $P$ value was calculated to reflect confidence in the detection call. The flag values were additionally exported as .chp files.

Affymetrix probe intensities were imported into GeneSpring (version 7.2, Agilent Technologies), where probeset signal values were calculated using the GC-RMA algorithm. Upon import of the Affymetrix flag values, the probesets were filtered to retain only those that were flagged as present in at least 2 of the repeat samples. This list was used for condition-based principle components analysis to assess global trends in sample similarity. This analysis demonstrated groupings based on sample identity and prompted the use of mixed-model 2-way ANOVA as a means of finding differentially regulated genes between the sites of interest.

GC-RMA signal data were imported into Partek Genomics Solution (version 6.2, Partek Inc.), where the data were $\log _{2}$ transformed. Probesets not shared between mouse and human chips were removed. Genes less than $P<0.05$ for the identity of sample term of the ANOVA, and with less than 2 -fold change between positive and negative populations, were also excluded. The resulting enriched gene lists for bulge, secondary hair germ, and CD200hilTGA6hi cells were then examined for intersection using Partek. Primary data are available at the Gene Expression Omnibus database (http://www.ncbi.nlm.nih.gov/geo/; GEO accession no. GSE21569).

\section{Hair reconstitution}

Hair reconstitution was performed as previously described (9). Briefly, epidermis from 7-week-old ROSA26 mice (Jackson Labs) was sorted to yield the identified population. Dermal preparations from 2-day-old neonate wild-type mice as previously described (27) were frozen in advance. Frozen dermal cells $\left(6 \times 10^{6}\right)$ were thawed, combined with the listed number of epidermal cells in $60 \mu \mathrm{l}$ PBS, and injected intradermally onto the backs of $S C I D$ mice. After 4 weeks, grafts were harvested and processed for $\beta$-galactosidase activity, paraffin embedded, and sectioned.

\section{Statistics}

For all $P$ value calculations, paired Student's $t$ test with a 1-tailed distribution was used, and $P$ values less than 0.05 were considered significant. All averages listed are mean \pm SEM.

\section{Acknowledgments}

We gratefully acknowledge the assistance of Charles H. Pletcher and William Murphy of the Penn Flow Cytometry and Cell Sorting 
Facility Core, Don Baldwin of the Penn Microarray Facility Core, Leroy Ash of the histology core, and the Penn Human Cooperative Tissue Network, which is supported by the National Cancer Institute. This research was supported in part by NIH grants R01-AR46837, P30-AR057217, and K08AR055666; Pennsylvania Department of Health (which specifically disclaims responsibility for any analyses, interpretations, or conclusions); the Edwin \& Fannie Gray Hall Center for Human Appearance at University of Pennsylvania Medical Center; the American Skin Association; the Dermatology Foundation; and L'Oreal.
Received for publication July 22, 2010, and accepted in revised form November 8, 2010.

Address correspondence to: George Cotsarelis, Department of Dermatology, Kligman Laboratories, M8 Stellar-Chance Bldg., 422 Curie Blvd., Philadelphia, Pennsylvania 19104, USA. Phone: 215.898.9967; Fax: 215.573.9102; E-mail: cotsarel@mail.med.upenn.edu.

Luis A. Garza's present address is: Department of Dermatology, Johns Hopkins School of Medicine, Baltimore, Maryland, USA.
1. Ito M, Kizawa K, Hamada K, Cotsarelis G. Hair follicle stem cells in the lower bulge form the secondary germ, a biochemically distinct but functionally equivalent progenitor cell population, at the termination of catagen. Differentiation. 2004; 72(9-10):548-557.

2. Ito $\mathrm{M}$, et al. Stem cells in the hair follicle bulge contribute to wound repair but not to homeostasis of the epidermis. Nat Med. 2005;11(12):1351-1354.

3. Lyle S, Christofidou-Solomidou M, Liu Y, Elder DE, Albelda S, Cotsarelis G. The C8/144B monoclonal antibody recognizes cytokeratin 15 and defines the location of human hair follicle stem cells. J Cell Sci. 1998;111(pt 21):3179-3188.

4. Tumbar T, et al. Defining the epithelial stem cell niche in skin. Science. 2004;303(5656):359-363.

5. Paus R, Cotsarelis G. The biology of hair follicles. NEngl J Med. 1999;341(7):491-497.

6. Price VH. Treatment of hair loss. NEnglJ Med. 1999; 341(13):964-973.

7. Cotsarelis G. Epithelial stem cells: a folliculocentric view. J Invest Dermatol. 2006;126(7):1459-1468.

8. Christiano AM. Epithelial stem cells: stepping out of their niche. Cell. 2004;118(5):530-532.

9. Morris RJ, et al. Capturing and profiling adult hair follicle stem cells. Nat Biotechnol. 2004;22(4):411-417.

10. Blanpain C, Lowry WE, Geoghegan A, Polak L, Fuchs E. Self-renewal, multipotency, and the existence of two cell populations within an epithelial stem cell niche. Cell. 2004;118(5):635-648.

11. Zhang YV, Cheong J, Ciapurin N, McDermitt DJ, Tumbar T. Distinct self-renewal and differentiation phases in the niche of infrequently dividing hair follicle stem cells. Cell Stem Cell. 2009;5(3):267-278.

12. Cotsarelis G, Sun TT, Lavker RM. Label-retaining cells reside in the bulge area of pilosebaceous unit: implications for follicular stem cells, hair cycle, and skin carcinogenesis. Cell. 1990;61(7):1329-1337.

13. Ohyama $M$, et al. Characterization and isolation of stem cell-enriched human hair follicle bulge cells. J Clin Invest. 2006;116(1):249-260.

14. Inoue $\mathrm{K}$, et al. Differential expression of stem-cellassociated markers in human hair follicle epithelial cells. Lab Invest. 2009;89(8):844-856.

15. Trempus CS, et al. Enrichment for living murine keratinocytes from the hair follicle bulge with the cell surface marker CD34. J Invest Dermatol. 2003; 120(4):501-511.

16. Poblet E, Jimenez F, Godinez JM, Pascual-Martin A, Izeta A. The immunohistochemical expression of CD34 in human hair follicles: a comparative study with the bulge marker CK15. Clin Exp Dermatol. 2006; 31(6):807-812.

17. Barrandon Y, Green H. Cell size as a determinant of the clone-forming ability of human keratinocytes. Proc Natl Acad Sci U S A. 1985;82(16):5390-5394.

18. Wagner JE, et al. Isolation of small, primitive human hematopoietic stem cells: distribution of cell surface cytokine receptors and growth in SCIDHu mice. Blood. 1995;86(2):512-523.

19. De Paiva CS, Pflugfelder SC, Li DQ. Cell size correlates with phenotype and proliferative capacity in human corneal epithelial cells. Stem Cells. 2006; 24(2):368-375.

20. Dolznig H, Grebien F, Sauer T, Beug H, Mullner EW. Evidence for a size-sensing mechanism in animal cells. Nat Cell Biol. 2004;6(9):899-905.

21. Tani H, Morris RJ, Kaur P. Enrichment for murine keratinocyte stem cells based on cell surface phenotype. Proc Natl Acad Sci U S A. 2000;
97(20):10960-10965.

22. Wilson A, et al. Hematopoietic stem cells reversibly switch from dormancy to self-renewal during homeostasis and repair. Cell. 2008;135(6):1118-1129.

23. Lyle S, Christofidou-Solomidou M, Liu Y, Elder DE, Albelda S, Cotsarelis G. Human hair follicle bulge cells are biochemically distinct and possess an epithelial stem cell phenotype. J Investig Dermatol Symp Proc. 1999;4(3):296-301.

24. Ozawa M, Aiba S, Kurosawa M, Tagami H. Ber-EP4 antigen is a marker for a cell population related to the secondary hair germ. Exp Dermatol. 2004; 13(7):401-405.

25. Jaks V, et al. Lgr5 marks cycling, yet long-lived, hair follicle stem cells. Nat Genet. 2008;40(11):1291-1299.

26. Greco V, et al. A two-step mechanism for stem cell activation during hair regeneration. Cell Stem Cell. 2009;4(2):155-169.

27. Zheng Y, Du X, Wang W, Boucher M, Parimoo S, Stenn K. Organogenesis from dissociated cells: generation of mature cycling hair follicles from skinderived cells. J Invest Dermatol. 2005;124(5):867-876.

28. Cotsarelis G, Millar SE. Towards a molecular understanding of hair loss and its treatment. Trends $\mathrm{Mol}$ Med. 2001;7(7):293-301.

29. Rittie L, Stoll SW, Kang S, Voorhees JJ, Fisher GJ. Hedgehog signaling maintains hair follicle stem cell phenotype in young and aged human skin. Aging Cell. 2009;8(6):738-751.

30. Demehri S, Kopan R. Notch signaling in bulge stem cells is not required for selection of hair follicle fate. Development. 2009;136(6):891-896.

31. Scholzen T, Gerdes J. The Ki-67 protein: from the known and the unknown. J Cell Physiol. 2000; 182(3):311-322. 